\title{
Unresolved conflicts and shaming processes: risk factors for long-term sick leave for mental-health reasons
}

\section{Lena Ede}

Department of Social and Psychological Studies

Karlstad University, Sweden

Eastern Norway Research Institute, Östlandsforskning

Lillehammer, Norway

lena.ede@kau.se

\section{Bengt Starrin}

Department of Social and Psychological Studies

Karlstad University, Sweden

bengt.starrin@kau.se

\begin{abstract}
Mental illness is the most common diagnosis resulting in long-term sick leave in Sweden today, especially stress-related syndromes and mood disorders. The aim of this article is to analyse the relational and emotional processes in the workplace that may contribute to the understanding of long-term sick leave for mental-health reasons. We conducted interviews with twenty-six people who were on sick leave because of diagnoses of mental ill health. The empirical material was analysed using Classic Grounded Theory. We suggest that the risk of being afflicted with mental illness, and forced into long-term sick leave, increases when there are conflicts at work that remain unresolved and which lead to malignant shaming processes that jeopardize personal dignity. In their struggle to maintain self-esteem, the afflicted escalate their work efforts by increasing work intensity, putting in overtime, and working when ill. Eventually, this behaviour affects their health and results in sicklisting. The strengths and weaknesses of the study are discussed along with the need for further research.
\end{abstract}


Keywords: mental illness, long-term sick leave, shaming processes, unresolved conflicts

\section{Introduction}

Between 1999 and 2003 there was a dramatic increase in long-term sick leave cases (>60 days) in Sweden. In 2010, the numbers began to increase again (Swedish Social Insurance Agency, 2010). The latest figures indicate a continued increase (Swedish Social Insurance Agency, 2013a). In 2005, diagnoses of mental illness replaced muscular and skeletal disorders as the most common grounds for sick leave (Swedish Social Insurance Agency, 2010; 2013b). Among diagnoses of mental illness, stress-related syndromes and mood disorders have been increasing (Swedish Social Insurance Agency, 2010). Internationally, stress-related illness is also on the increase (European Agency for Safety and Health at Work, 2013; Dollard et al., 2007). Throughout this period women have been on sick leave more than men. Women are also overrepresented in regard to diagnoses of mental illness.

There are several different explanatory models for the emergence of mental illness as the primary reason for long-term sick-listing. The demand control model, which deems imbalances between work demands and individual resources to be risky for people's health, and also a possible cause of sicklisting, is frequently used. Above all, this applies to a combination of high work demands, a lack of both control and opportunities for participation, and a low level of support from supervisors (Karasek \& Theorell, 1990). This model clearly shows that restructuring - involving streamlining, staff reduction, and accelerating the pace of work - is a risk factor not only for those made redundant but also for those kept on (European Agency for Safety and Health at Work, 2013; Westgaard \& Winkel, 2010; Theorell, 2009; Virtanen et al., 2007). In their literature study, Michie and Williams (2003) found that common causes of mental illness resulting in sick leave included long workdays, high tempo, and high demands in combination with lack of control over the work situation and few opportunities to influence it, especially if compounded with lack of support and unsatisfactory leadership. Also, other studies have found that leadership qualities and work group climate correlate with the risk for longterm sick leave (Clausen et al., 2012; Sandmark \& Renstig, 2010; Nyberg et al., 2008).

Several studies have observed the role of work-related conflicts as a source of mental illness. Romanov et al. (1996), for example, found a correlation between mental illness and conflicts at work. According to Hyde et al. (2006), unresolved conflicts or conflicts resolved through the use of authority are particularly risky. 
Another model focuses on the nature of the social relations between people, in accordance with social psychological theory in which stigma (Goffman, 1990) and dysfunctional shame (Scheff, 2013) are seen to be causes of mental illness. Shame signals a state of insecure social bonds, and can give rise to lasting conflicts if nothing is done to remedy the situation (Scheff, 1990). Studies show that people who have been ostracized, harassed, and humiliated or subjected to other forms of shaming run a greater risk of being afflicted with a mental disorder and sick-listed than people who have not suffered such treatment (e.g. Eriksson, Starrin, Ede \& Janson, 2011; Starrin, 2011; Starrin \& Wettergren, 2009).

There are comparatively few qualitative studies that focus on the role of emotional relations in the emergence of long-term sick leave with a diagnosis of mental illness. The purpose here is therefore to analyse the relational and emotional processes in the workplace that may contribute to our understanding of long-term sick leave for reasons of mental health.

\section{Method}

This study, which has an explorative approach, was launched in the spring of 2010. The data are derived from qualitative, individual interviews with a strategically selected group of women and men in a mid-Swedish region. The respondents were on long-term sick leave (at least 60 days but no more than 365 days) from permanent (at least part-time) positions for reasons of mental health. Their ages ranged from 29 to 58, with half of them being under 40 . They represent a great variety of professions and educational levels, evenly distributed between the private and public sectors. Nearly half of them are in health care and human services jobs. At the time of the interviews, more than half of them had returned to work part-time. Some had left their employment, generally voluntarily. The respondents have been allocated pseudonyms.

\section{Implementation}

The data collection, in the form of interviews with 26 persons (15 women and 11 men), was carried out in the spring of 2010. Two officials at the Social Insurance agency telephoned persons who were documented to have had been on sick leave for mental-health reasons. They gave information about the study and stressed that participation was voluntary. In all, 40 persons were contacted, of which 13 declined to participate. Their names and addresses were handed over to the research group, who in turn sent written information regarding the study, repeating that participation was voluntary. Some days later, the interviewers phoned the potential respondents, further informing them about the study, voluntary participation and the possibility to withdraw 
without stating a reason. On this occasion, one person declined. The time and place of each interview was set at this point.

Two persons, occasionally three, conducted the individual interviews, mostly in the respondents' homes, but with some taking place at the workplace (if they had returned to work) and some at the interviewer's workplace. We asked about the reasons for their sick-listing, their anamnesis, the nature of their relationships at work, and about any critical events in their workplaces. The interviews were conducted with great sensitivity to the respondents' own narratives. The goal was to capture their personal impressions of the causes of their sick-listings. The interviews were digitally recorded and the interviewers transcribed them immediately after they were done.

\section{Analysis}

The Classical Grounded Theory (CGT), which is a pattern-seeking method for analysing data, was used (Glaser, 1998). The aim of the CGT is to generate knowledge from data by coding and extracting conceptual labels and categories for patterns of human behaviour or phenomena (Glaser, 2011).

The analysis started with the open coding of data. The work of coding continued, and evolved into selective coding. The comparison of the codes and how they might be related to each other gave rise to an overarching category - unresolved work-related conflicts. In order to gain an overview of how the proposed categories were related to each other, analysis maps were constructed. The proposed model is presented in Figure 1. During the analysis, a number of codes emerged which indicated the importance of shame in the process of being ill, which prompted the use of Retzinger's (1991) shame markers.

\section{Ethical considerations}

The possibility of ethical issues was sharply in focus, as the interviews were likely to touch on delicate areas and difficult experiences. Nevertheless, we judged the benefits to outweigh the risks. The submission to the Regional Research Ethics Board in Uppsala was approved on 17 Feb. 2010. The respondents were informed by phone, mail, and on the occasion of the interview of the purpose of the study and their right to withdraw at any point, and were also assured of anonymity. Before the interview, they signed a consent form and were handed contact information for the research group. 


\section{Results}

We suggest that the risk of being afflicted with mental-health issues leading to sick-listing increases when there are unresolved conflicts at work that lead to malignant shaming processes that jeopardize personal dignity. In their struggle to maintain self-esteem, the afflicted escalate their work efforts by increasing work intensity, putting in overtime, and working when ill. Eventually, such patterns affect health and result in sick-listing. This usually long and drawn-out process should be understood in the context of restructuring in the form of streamlining, reduced staffing, and accelerating pace at work. The general features of the generated model and the focal concepts are presented in Figure 1.

\section{Figure 1}

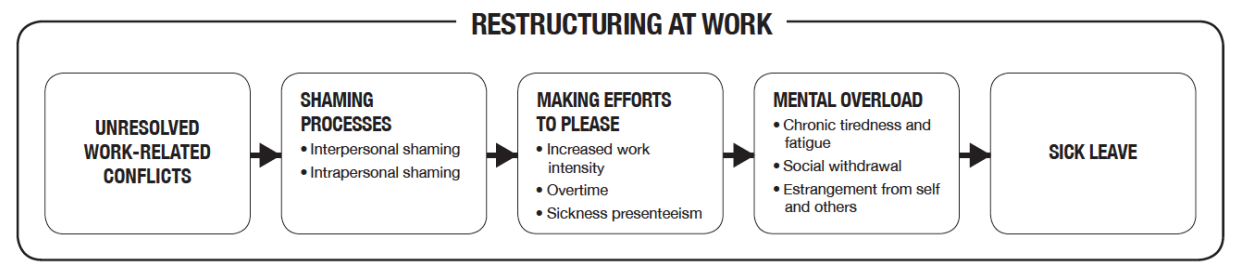

Figure 1: Model of the process propelled by drawn-out and unresolved relational conflicts at work leading to sick leave for mental-health reasons.

\section{Restructuring at work}

The background against which the events reported by the respondents in our study take place is made up of five changes. First, there is the change of business owner, supervisor or work team members. This requires closing old relationships and building new ones. Second, there are changes involving various forms of down-sizing, such as reducing staff (although not necessarily the workload). Third, there are changes related to the implementation of new technology and IT systems, which were supposed to facilitate work, but instead complicated it. Fourth, many of the respondents were given many new and/or more advanced tasks, in addition to their old ones, without either more time allocation or professional training. Fifth, there were increasing demands from customers or clients for employee availability.

Some of the respondents experienced all these changes, while others encountered only a few. It was taken for granted in the work place that these changes should take place alongside the regular flow of work, and that any 
interruption of productivity was unacceptable. All respondents shared the feeling that the changes were undesirable and impossible for them to influence.

However, having encountered changes in the workplace, with increasing demands and loss of control, is not sufficient to explain sick leave. The changes are part of the downward spiral leading to illness but they share a further common denominator: the experience of unresolved conflicts at work.

\section{Unresolved work-related conflicts}

We suggest that the risk of becoming involved in drawn-out work-related conflicts that remain unresolved increases when work-related changes take place over which employees have no control. We use the term 'work-related conflicts' to refer to conflicts between at least two parties in the workplace that are lasting and remain unresolved. These conflicts can be horizontal (between colleagues) or vertical (between supervisor and subordinate).

In our respondents' narratives, the horizontal conflicts were characterized as very bad atmospheres in the work groups or among colleagues. The spirit of the workplace changed from pleasant and unifying to competitive and 'prickly', as David puts it. Sune, who has experienced a major staff reduction, declares: 'Everyone wants to stay on. There is competition between those of us who have similar duties, work faster and perform the best.'

Other respondents gave accounts of disagreements over values-related issues, and differences of opinion on how joint work should be done. Further problems included scheming and conflicts, which the respondents were not themselves part of, but which affected them and the overall group spirit in their workplaces. In these cases, the buffer that collegial support can provide against problems at work has not been operative, and therefore feelings of exclusion and rejection have set in instead.

Vertical conflicts are, however, most prominent in our proposed model because of their inherent imbalance of power. The respondents, all in subordinate positions, tell stories about painful humiliations and maltreatment inflicted by their supervisors. Our emphasis will be on vertical conflicts which, we argue, when they remain unresolved, are a major contributor to shaming processes.

\section{Shaming processes}

Shaming is a relational process which can take place between persons, as an interpersonal process, or within a person, as an intrapersonal process. 
Analytically, we differentiate between these two shaming processes although they are interlinked. The interpersonal dimension of shaming is manifested in external abuse and humiliation and has an identifiable source, reflected in the expression 'he offended me'. The intrapersonal process, on the other hand, is subtler and occurs when the external abuse is internalized as part of people's expectations of themselves. They judge themselves, and feel that they are someone they do not want to be, or that they cannot manage their work as they did before. They feel worthless, which is reflected in negative selfesteem. We adopt Scheff's (1990) definition of shame as an umbrella term for a large group of emotions including less intense forms, such as embarrassment and more intense forms, such as humiliation, debasement and disgrace.

\section{Interpersonal shaming}

Interpersonal shaming involves condescending treatment in two forms of victimization. We define one as confrontational humiliation and the other as evasive humiliation Victimization is here used to designate acts producing feelings of degradation, humiliation, and belittlement.

Confrontational humiliation refers to encounters between a superior and a subordinate in which the superior directly voices dissatisfaction with the subordinate in a public forum or one-on-one situation, and which the subordinate perceives as unpleasant and hostile. Gustav has been subjected to this kind of treatment. From the very start of his employment he felt bullied and ostracized by his superiors as well as his co-workers. The antagonism escalated when his supervisor humiliated him in public. He was threatened with dismissal every time he did not do as the supervisor said. Another respondent who has had a similar experience of being treated badly by his superiors is Manuel, who stands accused of professional misconduct and is being prevented from completing his training without explanation. He feels unjustly treated and is upset at not having the opportunity to defend and explain himself.

Birgit also feels unjustly treated. She was severely reprimanded when she objected to the, in her opinion, unfair decision to relocate her to a different department. She explains: 'The boss said that I had a bad attitude, but I've never received any complaints. And I work so hard while others are surfing and playing games. I just cried and my whole body ached.'

Birger asked his supervisor for assistance to relieve an increasingly stressful work situation, but instead of providing help, the supervisor said: 'As an employee, you must do your assigned duties in the time allotted.' At that point, Birger's duties had not only increased in number, but had also changed from product development to sales and accounting without any form of further 
training. He was forced to work overtime to catch up. When the company was sold to a foreign owner, the demands increased further, and he was no longer paid for his overtime.

The second form of victimization - evasive humiliation - occurs when a superior with the authority to facilitate the work of a subordinate neglects to respond responsibly. 'We were promised help, but the help never materialized,' says Sune.

This type of victimization often involves supervisors who listen and show sympathy but, ultimately, ignore problems and avoid conflicts. Camilla provides another example of evasive behaviour. She has problems with her co-workers as well as her tasks, and has asked her supervisor repeatedly for help without result.

David tried to make his supervisor understand the consequences of a major staff reduction, which entailed more work and new tasks for him: 'When things were really tough last autumn, I said that I was very tired now, but he said aren't we all. It didn't help me.'

Generally, respondents set a high threshold before asking for help. There was a prevailing fear of appearing in an unfavourable light. When they finally did draw the attention of their supervisors' to their problems, they were often treated with hostility or just ignored, treatment which reinforced their feelings of not being good enough.

\section{Intrapersonal shaming}

Intrapersonal shaming processes have no directly identifiable source, but are incorporated into the self-assessment of being inadequate, often expressed with phrases like 'I'm not good enough', or, as Helen puts it: 'I feel as if I'm no longer a person that counts.' Karin does not feel like a competent co-worker either, and asks rhetorically: 'Everyone else can manage, so what's wrong with me?' And Birger explains: 'I was mad at myself for not managing what I thought I ought to manage. I worked harder and harder.'

The sense of falling short of expectations results in a mental process of shame leading to a compulsion to work harder. David says:

You are your own stick. A great deal of the problem lies with me. I want to deliver a perfect product and work until it's done, but it's getting more and more difficult to find the time. I'm ashamed to be doing a bad job.

It was important to the respondents to project an image of themselves as competent and capable co-workers, or as Helena puts it: 'I was devastated 
because I thought that they thought that I couldn't do my job. I don't want them to think that I'm less competent.'

\section{Making efforts to please}

Feeling of shame continues to grow stronger as the respondents try to hide it from themselves and others. They make great efforts to protect their bruised senses of self-esteem, and to please their employers. These efforts are an attempt by the respondents to present themselves in such a way that the employer will recognize and confirm that they are good enough. We label this activity 'making efforts to please'. Karin pushed herself to the limit to get such recognition:

I was constantly in pursuit of meeting the criteria for a raise. From the first day at work I have performed everything required, and yet I never reach the top. No matter how fast I run, I will never catch up.

Making efforts to please can take three forms: increased work intensity, overtime, and sickness presenteeism.

\section{Increased work intensity}

To avoid the shame of not managing tasks in time, work intensity is increased. This is done in two ways. One way is to 'work through the breaks', skipping lunch and/or the joint coffee breaks. Work allows no rest, and requires full concentration. 'I don't have time for a single private thought the whole day because the work demands my full attention,' Doris says. David puts it this way: 'Work spills over into leisure, but leisure is not allowed to trickle into the workplace.'

Another way of increasing the intensity of work is to increase the pace of work and race through the tasks. Some respondents try to do their extended tasks in a shorter time, so as not to fall behind. Others describe the never-ending demands of clients, customers, and other people in need. Gunnel, for example, has to receive more and more clients, which means less time for each one. She explains: 'They were in line outside my office and every interview required extra work.' Maria declares: 'The pace at work has been stepped up and we are expected to be available at all times.'

The respondents feel trapped in a situation that forces them to do a job at a level far below what they would consider acceptable, in terms of both quality and service. The intense pace at work led to short-term sick-listings among the employees, which in turn meant that the people still at work were forced to do more, since there were no substitutes available and the employer expected 
the work to be done as if everyone was there. The frustration involved in being swamped with work, with no chance of catching up during the regular work hours, is widespread among the respondents.

\section{Overtime}

Overtime is another example of an effort to please. When the tasks can no longer be completed during regular work hours, the workdays are extended. In this phase the strain becomes increasingly evident. Every task takes longer and people lose focus. There is a greater risk of making mistakes and/or lowering standards.

Victoria and Sara check their work constantly, for fear of forgetting something or making undetected mistakes. They often stay late at work to catch up. Others demonstrate their loyalty to employers by assuming responsibility far beyond duty and obligation. Doris has had such an experience:

When I have worked nearly all day, a customer calls to place a job order and then the supervisor promises that it will be delivered the same day. So even though I have worked all day I still have to stay on late into the evening to finish the job.

\section{Sickness presenteeism}

The effort to please often drives the respondents to work even when they should have stayed at home. This is referred to as sickness presenteeism. Ailments such as headache, muscle pain, cold, fever and dizziness are not seen as justification for absence from work. Most of the respondents have noticed bodily signals of illness over time, like Ingrid: 'I knew why I had a headache but I ignored the signal.' Sometimes Sune had to get his wife to help him get out of bed when he was stricken by lumbar-region backache. Karin put on sunglasses to protect her eyes and went to work despite having a severe migraine. Sara was so dizzy that she had to hold on to the walls when she walked down the corridor.

There are three primary types of reasons for going to work regardless of health status. Firstly, it is an issue of loyalty - to colleagues, since no substitutes would be called in - or to customers, clients, or care recipients, since there was a desire to not fail to provide them with service. Secondly, it is because the tasks were so specialized that no one else could do them, and they would be collecting dust together with the continuous stream of new cases to handle; 'There is twice as much on your return to work', says Karin. Thirdly, it is because of the shame of being ill, which is seen as showing 
weakness. This is a phenomenon that Birger has experienced: 'I didn't want to give up. I wanted to admit that I couldn't take it anymore.' Johan was so afraid of being dismissed that he didn't dare to stay at home, as this would reveal that he couldn't make it. He had nightmares about being fired. He says: 'No matter how I felt, I went to work. I set goals for each day to get the strength to work.'

\section{Mental overload}

Living up to expectations takes its toll, and the respondents came to be at a stage when health problems became an issue. The escalating spiral of increased workload and destructive relationships preyed on health and grew harder to cope with. Some felt physical symptoms such as palpitations, fatigue, headache, and dizziness, while others had mental symptoms such as apathy and despondency. Some experienced both types of symptoms. The disorders mainly appeared in three forms: chronic tiredness and fatigue, social withdrawal, and estrangement from self and others.

\section{Chronic tiredness and fatigue}

The respondents describe permanent tiredness, a loss of energy, and an insatiable need for sleep. Several testify to experiencing everyday life as 'embedded in fog'. David grapples with feelings of guilt because of his tiredness:

I have to rest when I get home and then I feel guilty because of the children. I'm nice to them but I have no energy to think of stuff to do, take them to the playground and so on. I feel bad about that.

Ingrid talks about a constant feeling of lack of energy:

Nothing was fun any more. It was hard to go to work and as hard to go home. I couldn't readjust. When I was about to leave work, I was so immersed in it that I felt there was no time to go home. Usually, I can switch over as I walk to the car but now I couldn't. Once I was just sitting in the car for an hour or so because I couldn't muster the energy drive out from the parking lot.

Others talk about intellectual challenges, as Victoria does: 'I lost my memory. I was absent'. Doris reread the same text several times without understanding what it said. Sara did not recognize her own handwriting, and many recount concentration difficulties and forgetfulness, for example Maria: 'When I got back to work after the weekend, I didn't remember how to use the phone.' 
Social withdrawal

Social withdrawal is a phase of dissociation from others. Even socializing with relatives is too stressful. 'I can barely cope with myself,' says Helena, who is normally a happy and outgoing person. David puts it like this: 'When I was off work, I wanted to be on my own. I didn't want to be with people, no parties, no festivities. I entered a bubble. People couldn't make contact with me.'

Maria stopped having coffee and lunch breaks with her colleagues: 'I closed the door because I couldn't stand being around people.' Some of the respondents stopped answering the phone when they get home. Anna, who normally likes to chat on the phone, asked her children to say that she was in the shower or not home, in order to avoid having a conversation.

The respondents also abandoned leisure activities because they needed their spare time to recuperate from work and muster energy for the next day, or as Ingrid says: 'I gave up everything I liked doing. I didn't have time to exercise; I gave up everything that can generate energy.' In Gunnel's case, her whole vacation was spent gathering energy for working in the autumn. She was lying still all the time to save energy: 'I went into hibernation like a bear to save energy.'

\section{Estrangement from oneself and others}

Mental overload generates a sense of being estranged from oneself and others. This is variously indicated, but most clearly in abrupt mood swings with elements of anger. Several of the respondents describe supressed anger, controlled at work but released at home. Karin had this experience: 'I kept up a front so no one noticed how I had changed except my husband and my child. I wasn't exactly a nice mum.' David shares this experience: 'At work I tried to be happy but when I got home my family was confronted with my worst sides. I don't feel good about that.' Others mention sudden and inexplicable bursts of crying: 'I never knew when it would happen,' says Helena, 'it just happened.'

Some were not aware of having changed until others told them. 'My daughters pointed out that I was never happy any more,' says Victoria. Birgit was told by her sister that she was 'absent and sad', and Camilla's husband said he thought that she had 'undergone a personality change', and that she was 'constantly angry'.

\section{Sick leave}

For most of the respondents, being sick-listed was not unexpected. Bodily signals had been evident for a long time, in some cases several years. They knew that the situation was untenable and would ultimately result in sick leave. 
Long-term sick leave, however, requires medical assessment. Most of the respondents went to see a doctor of their own accord, some on advice from others, and some for a routine check-up.

Johan contacted a doctor, but has no recollection of what happened - just that he was sick-listed: 'I felt like I had been run over by a train.' Gunnel took a week off to rest, but went to see a doctor when she failed to return to work. At that time she was so dizzy that she could hardly move: 'I felt intoxicated. My head was spinning and buzzing. All sounds were extremely sharp.' The doctor sick-listed her immediately. David felt completely drained of energy and went to see a doctor: 'There was a big black hole in my chest, or so it felt. This is it, I thought.'

The event that prompted Ingrid to seek treatment was when a colleague put his hand on her shoulder and asked how she was: 'I totally broke down and just cried. I couldn't stop crying.' He made her go to a doctor and she was sick-listed.

Birger was driving to work after a week on unspecified sick leave. He was ashamed to share with his colleagues the real reason for his absence, of not being able to cope with the stress of work: '... because I was extremely stressed but I didn't say that at work. I gave other reasons.' On a country road shortly before the workplace, he pulled over and stayed there until his live-in partner came and took him to a doctor.

When Karin was at the doctor's for a routine check-up, she brought up her health problems. The doctor said that she was a textbook example of fatigue depression and wanted her to go on sick leave, which she felt she did not have time for:

No, no that's unthinkable - and then she said that she would sick-list me starting from tomorrow, so I could finish things. I worked until six that evening and then I went home. And so it goes. It's frustrating not to cope. Now I have received confirmation that I was not good enough.

Common to all respondents is that they perceived the sick-listing as a failure, a shame. 'I lost face. Now everyone knows that I'm a fake,' says Gunnel. And Helena makes the following comments: 'Being sick-listed equals being weak. By saying that I have been on sick leave is also saying that I'm not resistant to stress. So, I'm not good enough. I'm weaker than others.'

\section{Discussion}

The aim of this article was to draw attention to the relational and emotional processes in the workplace which may contribute to our understanding of 
mental illness and long-term sick-listing for mental-health reasons. The study uses a Classic Grounded Theory approach.

We conclude that the risk of being afflicted with problems of mental health leading to sick-listing increases when there are drawn-out and unresolved conflicts in the workplace which, in turn, give rise to malignant shaming processes that jeopardize personal dignity. In their struggle to maintain selfesteem, the afflicted escalate their work efforts by increasing work intensity, working overtime, and working when ill. Eventually, this affects their health and results in sick-listing.

The suggested model has a bearing on Scheff's (2013) theory relating to the socio-emotional world. He maintains that recursive shame becomes dysfunctional and might also lead to mental ill health. We see unresolved work-related conflicts as a kind of psychological poison. This particular poison drains people of emotional energy, makes them anxious, afraid, ashamed and anxiety-ridden, which in turn generates further serious problems. Finally, the only solution, for many, is sick leave. Shame is a central factor for explaining the link between externally stressful events and illness, not least mental ill health.

Our understanding of the processes leading to mental illness has similarities with the research tradition that identifies high work demands and low participation as a combination causing illness (Karasek \& Theorell, 1990). The significant difference is that our model highlights the impact of conflict-ridden social relations on shaming processes. There are also similarities with studies that explicate the role of conflicts in understanding mental illness (Romanov, 1996), especially when the conflicts remain unresolved (Hyde et al., 2006).

Our model also displays many similarities with a study made by Eriksson et al. (2008), which emphasizes the role of social relations in understanding mental illness. In this case also, our study further develops the role of shaming processes.

Further intensive and extensive studies are needed. We have not, for instance, considered demographic factors or that which transpires outside the workplace. Future studies should also pay more attention to the relational processes that lead to dysfunctional and recursive shame processes, and how these are linked to mental ill health and sick leave.

\section{Acknowledgements}

This study was financed by the Nordic Research Council, via the Eastern Norway Research Institute, Lillehammer, and Karlstad University. 


\section{References}

Clausen, T., Nielsen, K., Carneiro, I.G., \& Borg, V. (2012). Job demands, job resources and long-term sickness absence in the Danish eldercare services; A prospective analysis of register-based outcomes. Journal of Advanced Nursing, 68(1), 127136.

Dollard, M., Skinner, N., Tuckey, M. R., \& Baily, T. (2007). National surveillance of psychosocial risk factors in the workplace: An international overview. Work \& Stress, 21(1), 1-29.

Eriksson, U-B., Starrin, B., \& Janson, S. (2008). Long-term sickness absence dueto burnout: Absentees' experiences. Qualitative Health Research, 18(5), 620-632.

Eriksson, U-B., Starrin, B., Ede, L., \& Janson, S. (2011). Social bonds, emotional processes and mental ill-health. In H. Nordby, R. Rönning, \& G. Tellnes (Eds.), Social aspects of illness, disease and sickness absence. Oslo: Unipub.

European Agency for Safety and Health at Work (2013). Priorities for occupational safety and health research in Europe: 2012-2020. Luxembourg: Publications Office of the European Union.

Glaser, B.G. (1998). Doing grounded theory: issues and discussions. Mill Valley, CA: Sociology Press.

Glaser, B.G. (2011). Getting out of data: Grounded Theory Conceptualization. Mill Valley, CA: Sociology press.

Goffman, E. (1963). Stigma: Notes on the Management of Spoiled Identity. New York: Simon \& Schuster.

Hyde, M., Jappinen, P., Theorell, T., \& Oxenstierna, G (2006). Workplace conflict resolution and the health of employees in the Swedish and Finnish units of an industrial company. Social Science \& Medicine, 63(8), 2218-2227.

Karasek, R., \& Theorell, T. (1990). Healthy work, stress, productivity and the reconstruction of working life. New York: Basic Books.

Michie, S., \& Williams, S. (2003). Reducing work related psychological ill health and sickness absence: a systematic literature review. Occupational and Environmental Medicine, 60, 3-9 doi: 10.1136/oem.60.1.3.

Nyberg, A., Westerlund, H., Magnusson Hansson, L. L., \& Theorell, T. (2008). Managerial leadership is associated with self-reported sickness absence and sickness presenteeism among Swedish men and women. Scandinavian Journal of Public Health, 36(8), 803-811

Retzinger, S. (1991). Violent Emotions: Shame and Rage in Marital Quarrels. London: Sage Publications.

Romanov, K., Appelberg, K., Honkasalo, M-J., \& Koskenvuo. (1996). Recent interpersonal conflict at work and psychiatric morbidity: a prospective study of 
15,530 employees aged 24-62. Journal of Psychosomatic Research, 40(2), 169176.

Sandmark, H., \& Renstig, M. (2010). Understanding long-term sick leave in female white-collar workers with burnout and stress-related diagnoses: a qualitative study. BMC Public Health, 10, 210.

Scheff, T. J. (2013). A social/emotional theory of 'mental illness'. International Journal of Social Psychiatry, 59(1), 87-92.

Swedish Social Insurance Agency (Försäkringskassan). (2010). Långtidssjukskrivna. Beskrivande statistik 1999-2009: kön, ålder, arbetsmarknadsstatus, sjukskrivningslängd och diagnospanorama. Socialförsäkringsrapport [Long-term sick leave: Descriptive statistics 1999-2009: gender, age, labour-market status, length of sick-listing, and panorama of diagnoses, Social-Insurance Report] 2010:16. Stockholm: Försäkringskassan.

Swedish Social Insurance Agency (Försäkringskassan). (2011). Försäkringsmedicinska beslutsstödet. En långtidsuppföljning av förändringar i sjukskrivningsmönster. Socialförsäkringsrapport [Medical-insurance support: a long-term following-up of changes in sick-listing patterns, Social Insurance Report] 2011:7. Stockholm: Försäkringskassan.

Swedish Social Insurance Agency (Försäkringskassan). (2013a). www.forsakringskassan.se/statistik/sjuk/manadsuppfsjuk/!ut/p/b1/jZDbcolwGl... , 22.08.2013

Swedish Social Insurance Agency (Försäkringskassan). (2013b) Socialförsäkringen i siffror 2013 [Social insurance in numbers 2013]. Stockholm: Försäkringskassan.

Starrin, B. (2011). Skam, stigma och psykisk ohälsa [Shame, stigma, and psychological health]. In N. Sundgren \& A. Topor (Eds), Psykiatri som social verksamhet [Psychiatry as social action], Stockholm: Bonnier Utbildning AB.

Starrin, B., \& Wettergren, Å. (2010). The Dynamic of Shame and Psychiatric III-Health. In G. R. Jackson, (Ed). Psychology of Neuroticism and Shame. New York: Nova Science Publishers

Theorell, T. (2009). Det svenska 1990-talet i ett stressmedicinskt perspektiv. Arbetsmarknad och Arbetsliv [The Swedish 1990s in a medical perspective of stress], 15(4), 43-56.

Virtanen, M., Vahtera, J., Pentti. J., Honkonen, T., Elovainio, M., \& Kivimäki, M. (2007). Job strain and psychological distress influence on sickness absence among Finnish employees. American Journal of Preventive Medicine, 33(3), 182-187.

Westgaard, R.H., \& Winkel, J. (2011). Occupational musculoskeletal and mental health: significance of rationalization and opportunities to create sustainable production systems - A systematic review. Applied Ergonomics, 42(2), 261-296. 